\title{
A qualitative study of men's perception and attitudes towards weight management and weight management services
}

\author{
P. Thorp ${ }^{1}$, P. Elliott ${ }^{2}$ and B. Ellahi ${ }^{3}$ \\ ${ }^{1}$ Cheshire and Wirral Partnership NHS Foundation Trust, Chester Gates, Chester CH1 6LT, UK, ${ }^{2}$ Cheshire and Wirral \\ Partnership NHS Foundation Trust, Liverpool Road, Chester CH1 1HJ, UK and ${ }^{3}$ Department of Biological Sciences, \\ University of Chester, Parkgate Road, Chester CHI 4BJ, UK
}

Obesity is a serious threat to public health in the UK with huge cost implications to the National Health Service and wider society ${ }^{(1)}$. In the Western Chesshire area $44.9 \%$ of males are obese and overweight yet only $25 \%$ of referrals to the local NHS commissioned weight management service (in 2009) were for men ${ }^{(2,3)}$. The aim of the present qualitative study is to investigate men's perceptions and attitudes towards weight management; identify at what stage men take up weight management services and why; explore barriers to attending weight management services and formulate recommendations for service development.

Eleven white British adult males aged between 27 and 59 years of age participated in one-to-one semi-structured interviews, based on a topic guide drawn from a review of the literature. All participants were from the same workplace setting and primarily Local Government Officers, with desk based jobs, but differing levels of seniority and complexity of role. Two participants had a healthy Body Mass Index, seven were overweight and two were in obese category 1. Interviews were recorded and transcribed. Framework analysis was used to make sense of the themes that emerged ${ }^{(4)}$. Ethical approval was gained from the University of Chester, Research Ethics Committee.

Participants viewed weight management as important for health but the pursuit of a healthy body mass index was not a consideration for the majority, who instead set their own parameters for a healthy weight. Appearance and image were important motivators but the men noted that they did not feel pressure to conform to a particular ideal. Being able to take part in sports or activity to maintain fitness was considered more important than looks. Changing priorities along the lifespan presented individuals with different challenges for managing their weight. It is noteworthy that the view that maintaining one's health through a diet and exercise regime was regarded as 'work'. Men viewed traditional weight management practices, such as calorie counting and weighing oneself in public, as being aimed at women and preferred to put the emphasis on physical activity rather than diet when managing their weight. Participants viewed weight management as a personal responsibility and would not attend the health service for support unless it was associated with other symptoms. Flexible, expert and personalised services that went beyond the general healthy eating and exercise messages were preferred.

A 'one size fits all' weight management approach will not be sufficient if services are to attract and engage men in health behaviour change.

1. Butland B, Jebb S, Kopelman P, McPherson K, Thomas S, Mardell J, et al. (2007) Tackling Obesities: Future Choices (Technical Report): Foresight.

2. Western Cheshire Primary Care Trust (2007). Adult Obesity in Western Cheshire Report http://www.westcheshiretogether.org.uk/pdf/Health\% 20Inequalities $\% 20$ Action $\% 20$ Plan.pdf.

3. Peters G (2009) Step by Step Healthy Weight and Lifestyle Programme Annual Report Western Cheshire Primary Care Trust.

4. Pope C, Ziebland S, Mays N (2006). Analysing qualitative data. In C Pope \& N Mays (Eds.) Qualitative Research in health care (pp. 72-74) Oxford: Blackwell Publishing. 